\title{
ABUNDÂNCIA DO BACTERIOPLÂNCTON E SUAS RELAÇÕES COM FATORES FÍSICO-QUÍMICOS E BIOLÓGICOS EM NOVE LAGOS RASOS DO CAMPUS CARREIROS - FURG, RIO GRANDE - RS (BRASIL)
}

\author{
NEUSIANE CHAVES DE SOUZA ${ }^{1,2}$ \& PAULO CESAR ABREU ${ }^{1,3}$ \\ ${ }^{1}$ Universidade Federal do Rio Grande - Instituto de Oceanografia - Laboratório de Fitoplâncton e Microorganismos Marinhos. \\ CxPostal: 474, 96201-900 - Rio Grande- RS, Brasil. ${ }^{2}$ neusianebio@ hotmail.com; ${ }^{3}$ docpca@furg.br
}

\begin{abstract}
Neste estudo procurou-se determinar quais fatores controlam a abundância de bactérias livres (BL) e aderidas a partículas (BA) em nove lagos presentes no Campus Carreiros da FURG, na região sul da planície costeira do Rio Grande do Sul. Concentração de oxigênio dissolvido, seston, nutrientes dissolvidos (amônia, nitrito, nitrato e fosfato), clorofila a e a abundância de bactérias, flagelados e ciliados foram determinadas em uma única coleta realizada em 10 de setembro de 2007. Não foi encontrada relação direta entre a concentração da clorofila a e a abundância bacteriana, o que permite supor que o principal aporte de carbono orgânico dissolvido para as bactérias é proveniente da decomposição da matéria orgânica oriunda da decomposição de macrófitas aquáticas e de plantas do entorno dos lagos. Contudo, foi observada uma relação inversa entre o oxigênio dissolvido e as BA, além de uma relação direta destas com o seston. Também foi encontrada uma relação positiva entre as BA e os flagelados heterotróficos e ciliados, indicando um possível controle "Top-Down". Já as BL apresentaram uma correlação positiva apenas com a concentração de fosfato dissolvido, caracterizando um controle "Bottom-Up".
\end{abstract}

RESUMO

PALAVRAS CHAVES: bacterioplâncton, lagos rasos, fatores bióticos, fatores abióticos

\begin{abstract}
Bacterioplankton abundance and its relationship with biotic and abiotic factors

in nine shallow lakes of Carreiros Campus - FURG, Rio Grande - RS (Brazil)

In this study we aimed to determine which factors control the abundance of free (FB) and attached bacteria (AB) in nine lakes at the Campus Carreiros of the Federal University of Rio Grande - FURG. Dissolved oxygen, seston weight, dissolved inorganic nutrients (ammonia, nitrite, nitrate and phosphate), chlorophyll a and the abundance of bacteria, flagellates and ciliates were investigated in a sample carried out in all lakes on September 10th 2007. There was no direct relationship between chlorophyll a and bacterial abundance, indicating that the main dissolved organic carbon source for bacteria comes from the decomposition of macrophytes and plants present in the lakes, or in their surroundings. However, it was observed a negative relationship between $A B$ and oxygen, and a direct correlation between this kind of bacteria and seston loads. Similarly, there was a direct relationship between $A B$ and flagellates and ciliates, suggesting a possible "Top-Down" control of attached bacteria in the lakes. On the other hand, FB were positively related to the phosphate concentration, indicating a possible "Bottom-Up" control.
\end{abstract}

KEY WORKS: bacterioplankton, shallow lakes, biotic factors, abiotic factors

\section{INTRODUÇÃO}

A maioria dos lagos tendem, ao longo do tempo, a ser preenchidos com sedimentos do ambiente terrestre. Acompanhado do fluxo de sedimento existe o fluxo de nutrientes, como o de fósforo e nitrogênio, os quais colaboram para o aumento da produtividade do sistema. Tal processo é conhecido como eutrofização (Esteves 1998).

Às bactérias cabe a função de decomposição e mineralização não só da matéria orgânica formada pela produção primária autóctone, mas também da matéria orgânica particulada proveniente do entorno dos lagos, permitindo que os nutrientes inorgânicos sejam reaproveitados pelos produtores primários (Esteves 1998). Além disso, as bactérias são um importante componente na cadeia alimentar planctônica, o que pode ter um grande impacto no funcionamento do ecossistema, com uma participação quantitativa significante no fluxo da energia e matéria destes ecossistemas (Azam et al.
1983, Mesquita 1987, Sanders et al. 1992). Esta participação das bactérias nas cadeias alimentares passou a ser conhecida como o conceito do "microbial loop" (alça microbiana), que ressalta a importância das bactérias na disponibilização da matéria orgânica para níveis tróficos superiores, através da absorção do carbono orgânico dissolvido e na transferência desta matéria para outros níveis a partir da sua predação, principalmente, por flagelados e estes por ciliados (Azam et al. 1983).

Em relação às fontes de carbono para 0 bacterioplâncton, alguns estudos têm destacado que, em lagos rasos e pequenos, o principal aporte é oriundo do detrito orgânico proveniente da bacia de drenagem e da decomposição das macrófitas aquáticas (Faria \& Esteves 2001, Anésio et al. 2003, Farjalla et al. 2006). Contudo, a produção de matéria orgânica dissolvida pelo fitoplâncton também pode colaborar com o crescimento de tal comunidade (Brönmark \& Hansson 1999, César \& Abreu 2001, Farjalla et al. 2006, Gao et al. 2007, Passow et al. 2007). 
Além do carbono orgânico dissolvido, outros nutrientes como o nitrogênio e fósforo, têm se mostrado importantes como limitantes ao crescimento bacteriano, caracterizando um controle "Bottom-Up" (Tzaras \& Pick 1994, Farjalla 2001), enquanto que entre os mecanismos bióticos, destacam-se a predação e a infecção por vírus, ambos denominados como controle "Top-Down" (Felip et al. 1996).

Mesmo com o incremento dos estudos sobre o bacterioplâncton, ainda sabemos pouco sobre a sua dinâmica, já que esses microorganismos possuem uma alta capacidade de ajustar rapidamente seu crescimento de acordo com mudanças ambientais (Cesar \& Abreu 2001). Além disso, não se pode esquecer a complexidade da comunidade microbiana no que se refere à diversidade de espécies e de formas.

O Campus Carreiros da Universidade Federal do Rio Grande vem sendo modificado por inúmeras atividades humanas desde sua implantação na década de 1970, dentre elas, plantações de árvores exóticas, construção de prédios e retirada de areia para a construção dos mesmos. Desta forma, neste local são encontrados muitos lagos rasos, cuja origem é a retirada de areia e/ou os alagamentos pluviais contínuos.

As distintas características tróficas destes lagos permitem que estudos comparativos sejam realizados em uma única área sujeita às mesmas condições climáticas, porém em lagos com distintas características fisiográficas e tróficas. Alguns estudos já foram realizados em alguns destes lagos, entre eles, recentemente, Santos (2003) comparou o fitoplâncton em nove lagos do Campus Carreiros. O autor observou diferenças na composição taxonômica e na densidade das microalgas destes ambientes.
Também foi observada uma relação positiva do teor de clorofila a com a concentração do nitrogênio.

Não existe, porém, qualquer informação sobre o bacterioplâncton e protozooplâncton destes ambientes aquáticos. Neste estudo, portanto, procurou-se determinar a abundância de bactérias livres e aderidas a partículas nos diferentes lagos do Campus Carreiros da FURG e determinar quais fatores controlam a abundância destes microorganismos nestes ambientes.

\section{MATERIAL E MÉTODOS}

\section{Área de Estudo:}

O Campus Carreiros da Universidade Federal do Rio Grande, com uma área de 240 hectares, localiza-se no município do Rio Grande, na região sul da planície do Rio Grande do Sul (3201' 44" S e $52^{\circ}$ 40 " 05' W). Esta região possui clima temperado quente e úmido, onde a média anual de temperatura é de $17^{\circ} \mathrm{C}$, com maiores médias mensais de precipitação no inverno e na primavera (Seeliger \& Odebrecht 1998).

Para o presente trabalho foram escolhidos nove lagos (L1, L2, L3, L4, L5, L6, L7, L8 e L9) no Campus Carreiros da Universidade Federal do Rio Grande (Figura 1). Os lagos se diferenciam pelo tamanho, morfologia, vegetação e estado trófico. Todos os ambientes são rasos, sendo a profundidade máxima em torno de $2 \mathrm{~m}$. Alguns lagos estudados são perenes, enquanto que outros são mais susceptíveis às variações climáticas anuais, podendo desaparecer em épocas de seca (L2, L3, L4). Alguns deles possuem vegetação arbórea em suas margens, diminuindo a ação dos ventos (L6) e causando sombreamento (L9). 


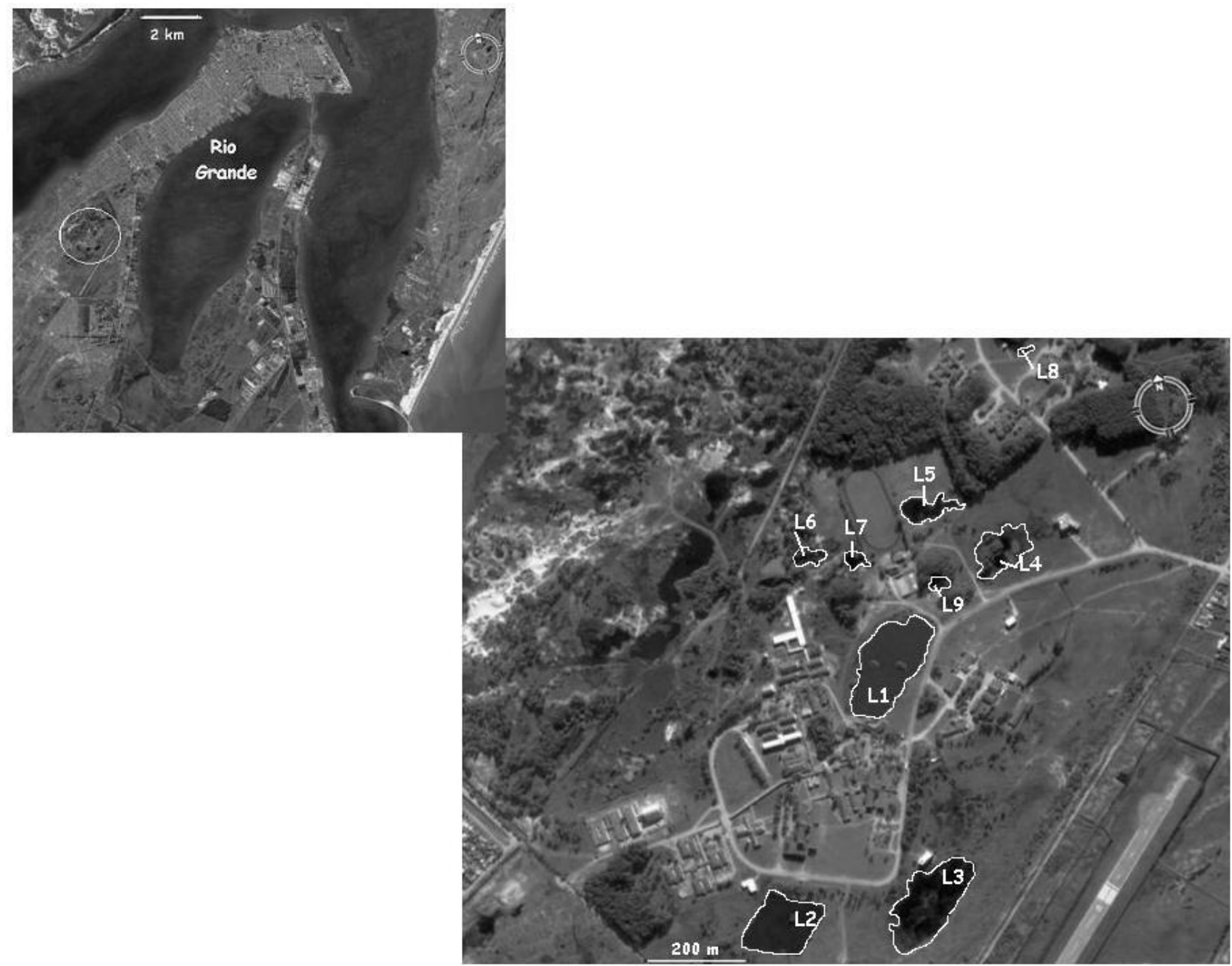

Figura 1: Localização dos nove lagos do Campus Carreiros da FURG (3201'44”' S e 52 $42^{\circ}$ " $05^{\prime}$ W).

Dentre os lagos estudados alguns são classificados como eutróficos-hipereutróficos, como é o caso do Lago dos Biguás (L1), onde é comum o crescimento maciço de cianobactérias durante o verão, ou em períodos de ventos intensos (Trindade 2005). Outros, com formação mais recente, ainda possuem algumas características oligo-mesotróficas, como é o caso do Lago Polegar (L2), o qual teve origem há aproximadamente 13 anos. O lago L7 era considerado um ambiente com características mesotróficas (Santos 2003), porém este está conectado ao Lago dos Biguás (L1) desde o ano de 2006. Tal ligação foi realizada com o objetivo de evitar alagamentos e tem provocado mudanças em suas características.

A presença de macrófitas aquáticas é uma característica comum nos lagos estudados. No lago L9, por exemplo, a macrófita aquática Azolla filliculoides forma tapetes mais ou menos compactos que cobrem parte da superfície da água. Esta macrófita vive em simbiose com a cianobactéria do gênero Anabaena, a qual tem a capacidade de fixar o nitrogênio atmosférico (Cordazzo \& Seeliger 1995).

\section{Amostras de Água:}

As amostras de água foram coletadas no início da tarde do dia 10/09/2007 em um único ponto de cada lago na sub-superfície da coluna d'água da região litorânea. As amostras foram tomadas com galões identificados e imediatamente levadas para o Laboratório de Ecologia do Fitoplâncton e de Microorganismos Marinhos do Instituto de Oceanografia da FURG. Para a análise dos microorganismos, sub-amostras de água foram colocadas em duas garrafas de vidro de cor âmbar (100 ml), uma contendo lugol (2\%) e outra com formol (4\%). Outra parcela da água foi filtrada e dividida em três garrafas de polietileno $(250 \mathrm{ml})$, as quais foram congeladas para posterior análise dos nutrientes (fósforo, nitrato e nitrito) em duplicatas. O restante da 
água foi utilizado imediatamente após a coleta para a análise da clorofila a, seston e nitrogênio amoniacal em triplicatas.

\section{Parâmetros Físico - Químicos e Clorofila a}

Durante as amostragens em campo foram realizadas medidas de temperatura com termômetro de mercúrio $\left(+/-0,5{ }^{\circ} \mathrm{C}\right)$ (Incoterm) e logo após, no laboratório, foram realizadas as medições de oxigênio dissolvido (Oxímetro Digimed DM-4P), pH (Digimed $\mathrm{DMpH} 3$ ) e condutividade (YSI model-33).

O teor de clorofila a foi determinado fluorimetricamente (fluorímetro Turner 111 calibrado) após filtração da água em filtro de fibra de vidro Whatman GF/F e extração do pigmento com acetona $90 \%$ no escuro e a $-12^{\circ} \mathrm{C}$, por 24 horas. A concentração do pigmento foi determinada segundo Welschmeyer (1994).

A medição do seston para cada amostra foi realizada conforme o método descrito por Strickland \& Parsons (1972), com a utilização de filtros de fibra de vidro Whatman GF/F previamente secos e pesados.

Medidas de nutrientes dissolvidos (nitrogênio amoniacal, nitrato, nitrito e fósforo) foram realizadas utilizando alíquotas da água filtrada em filtro de fibra de vidro Whatman GF/F (+/- 0,5mm). O nitrito e o fosfato foram determinados conforme metodologia descrita em Strickland \& Parsons (1972). Já o nitrato foi determinando somente após redução do mesmo a nitrito utilizando-se coluna redutora de cádmio (Strickland \& Parsons 1972), com uma pequena modificação do método que consiste na utilização do cloreto de amônia e não EDTA como ativador. As análises de nitrogênio amoniacal foram realizadas imediatamente após a coleta de acordo com a metodologia descrita em UNESCO (1983).

\section{Abundância de Bactérias, Flagelados e Ciliados}

Para obter a densidade de bactérias foi utilizada microscopia de epifluorescência (microscópio Zeiss Axioplan com filtro azul 487709 BP 450 - 490; FT 510; LT 520). Alíquotas de água (1 $\mathrm{ml}$ ) fixadas com formol neutro (4\%) foram filtradas em filtro de membrana escurecidas Nuclepore $(0,2 \mu \mathrm{m}) \mathrm{e}$ coradas com o fluorocromo Laranja de Acridina
(Hobbie et al. 1977). As bactérias livres e aderidas às partículas foram contadas em pelo menos 30 campos escolhidos aleatoriamente.

Para a contagem de flagelados e ciliados foram utilizadas amostras fixadas com lugol neutro (2\%) concentradas em câmaras de sedimentação por 24h e analisadas em microscópio invertido (Axiovert 135), segundo Utermöhl (1958). Uma vez que as reservas de amido dos organismos autotróficos são coradas pelo lugol, foi possível, durante a quantificação dos flagelados, diferenciá-los em heterotróficos e autotróficos.

\section{Análise Estatística}

Os dados foram plotados em gráficos de dispersão e determinada a Correlação de Pearson com o respectivo Coeficiente de Determinação $\left(r^{2}\right)$. Foram adotados o nível de significância $p<0,05$ e o intervalo de confiança de $95 \%$ para as relações observadas (Snedecor \& Cochran 1980). Como os valores da abundância de bactérias e da concentração de fosfato dissolvido dos lagos L1 e L7, foram muito superiores aos encontrados nos outros lagos, também foram feitos gráficos de dispersão sem os valores correspondentes a estes lagos.

\section{RESULTADOS}

\section{Fatores Físicos - Químicos e Clorofila a}

Os valores de temperatura da água foram similares em todos os lagos (Tabela 1). Na maioria dos lagos a temperatura foi de $24{ }^{\circ} \mathrm{C}$ e a menor foi de $19^{\circ} \mathrm{C}$ no lago L8.

As menores concentrações de seston (5,6 e 6,8 mg. $L^{-1}$ ) foram encontradas nos lagos L9 e L3, respectivamente, e as maiores nos lagos L6 $(315,8$ $\left.\mathrm{mg} \cdot \mathrm{L}^{-1}\right)$ e L8 $\left(159,71 \mathrm{mg} \cdot \mathrm{L}^{-1}\right)$ (Tabela 1). Em contrapartida, nestes dois últimos lagos, foram medidos os menores valores de oxigênio dissolvido, com 2,6 mg. $\mathrm{L}^{-1}$ no lago L8 e 3,2 mg. $\mathrm{L}^{-1}$ no L6. Nos demais lagos os valores de oxigênio dissolvido variaram entre 6,1 e 8,6 mg. $\mathrm{L}^{-1}$ (Tabela 1). 
Tabela 1. Variáveis ambientais observadas em nove lagos do Campus Carreiros - FURG no dia 10 de setembro de 2007.

\begin{tabular}{|c|c|c|c|c|c|c|c|c|c|}
\hline & L1 & L2 & L3 & L4 & L5 & L6 & L7 & L8 & L9 \\
\hline Temperatura da água $\left({ }^{\circ} \mathrm{C}\right)$ & 24 & 24 & 24 & 24 & 24 & 20 & 24 & 19 & 21 \\
\hline Seston (mg. $\mathrm{L}^{-1}$ ) & 11,3 & 15,5 & 6,8 & 13,8 & 15,7 & 315,8 & 14,8 & 159,7 & 5,6 \\
\hline Oxigênio $\left(\mathrm{mg} \cdot \mathrm{L}^{-1}\right)$ & 8,6 & 7,7 & 8,1 & 7,2 & 7,5 & 3,2 & 8,5 & 2,6 & 6,1 \\
\hline $\mathrm{pH}$ & 9,4 & 8,8 & 8,7 & 7 & 6,5 & 5,5 & 8,6 & 6,4 & 5,9 \\
\hline Condutividade ( $\mu$ mhos) & 180 & 95 & 90 & 210 & 75 & 190 & 180 & 185 & 150 \\
\hline Amônio $(\mu \mathrm{M})$ & 5,25 & 3,66 & 3,524 & 3,32 & 11,26 & 9,56 & 10,1 & 11,82 & 0,82 \\
\hline Nitrito $(\mu \mathrm{M})$ & 0,01 & 0,01 & 0,01 & 0,04 & 0,01 & 0,03 & 0,02 & 0,03 & 0,05 \\
\hline Nitrato $(\mu \mathrm{M})$ & 0,69 & 0,83 & 0,64 & 0,6 & 2,6 & 0,85 & 0,89 & 0,83 & 1,24 \\
\hline Fosfato $(\mu \mathrm{M})$ & 10,94 & 1,17 & 1,36 & 1,1 & 1,11 & 1,11 & 5,08 & 2 & 2,55 \\
\hline Clorofila a $\left(\mu \mathrm{g} \cdot \mathrm{L}^{-1}\right)$ & 40,5 & 8,3 & 7,8 & 54,8 & 15,9 & 169,1 & 50,8 & 48,4 & 50,2 \\
\hline
\end{tabular}

$\mathrm{O} \mathrm{pH}$ variou de básico $(9,4$ em L1) a ácido $(5,5$ em L6) (Tabela 1), tendo uma média de 7,4. A condutividade teve um mínimo de $75 \mu$ mhos (L5) e um valor máximo de $210 \mu$ mhos (L4) (Tabela 1).

Pôde ser observada uma alta variabilidade em relação à concentração dos nutrientes dissolvidos. $\mathrm{A}$ maior concentração do íon amônio foi de 11,8 $\mu \mathrm{M}$ (L8) e a menor foi de 0,8 $\mu \mathrm{M}$ (L9) (Tabela 1). A concentração de nitrito variou de $0,01 \mu \mathrm{M}$ a $0,05 \mu \mathrm{M}$ (L9) (Tabela 1), enquanto que os valores de nitrato dissolvido variaram de 0,6 $\mu \mathrm{M}$ (L4) a 2,6 $\mu \mathrm{M}$ (L5) (Tabela 1). O maior valor de fosfato dissolvido foi medido no lago $L 1(10,9 \mu \mathrm{M})$ seguido pelo lago $L 7$ $(5,1 \mu \mathrm{M})$, enquanto que o menor foi de $1,1 \mu \mathrm{M}$ (L2,
L4, L5 e L6) (Tabela 1).

Os valores de clorofila a foram bastante elevados e variaram muito entre os lagos. No lago L3 foi medido o menor valor $\left(7,8 \mu \mathrm{g} \cdot \mathrm{L}^{-1}\right)$, enquanto que no lago $\mathrm{L6}$ foi medido o maior $\left(169,1 \mu \mathrm{g} \cdot \mathrm{L}^{-1}\right)$ (Tabela 1).

\section{Abundância de bactérias, flagelados e ciliados}

A abundância de bactérias livres (Figura 2) foi maior no lago $\mathrm{L} 1\left(7,9 \times 10^{6}\right.$ org. $\left.\mathrm{mL}^{-1}\right)$ e menor no lago L8 $\left(1,68 \times 10^{6}\right.$ org. $\left.\mathrm{mL}^{-1}\right)$. As formas encontradas para o bacterioplâncton de vida livre foram cocos, bacilos, víbrios e filamentosas, sendo a forma cocos a dominante $(59,5-75 \%)$.

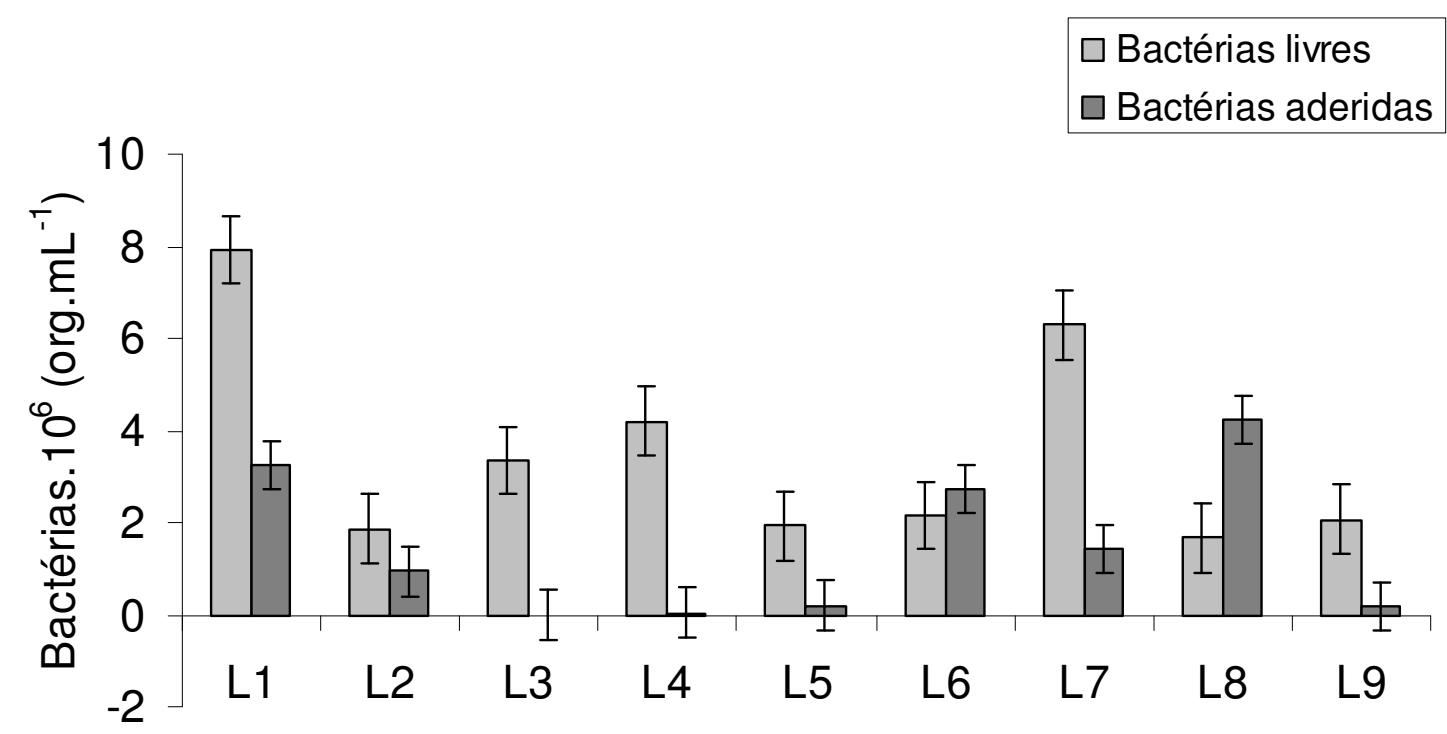

Figura 2: Densidade média de bactérias livres e aderidas ( \pm erro padrão) (x $10^{6} \mathrm{org} \cdot \mathrm{mL}^{-1}$ ) em noves lagos do Campus Carreiros em 10 de setembro de 2007. 
Apenas em dois lagos (L6 e L8), a densidade de bactérias aderidas a partículas superou a densidade de bactérias livres (Figura 2). Seu maior valor foi de $4,2 \times 10^{6}$ org. $\mathrm{mL}^{-1}$ (L8) e o menor foi de $5,5 \times 10^{3}$ org. $\mathrm{mL}^{-1}$ (L4). No lago L3 não foram encontradas formas aderidas.

Os flagelados foram divididos em duas classes: autotróficos e heterotróficos. A abundância de tais microorganismos foi muito variável (Figura 3 ), sendo que o menor valor para os flagelados autotróficos foi de $8,6 \times 10^{2}$ org. $\mathrm{mL}^{-1}$ (L3) e o maior foi de $28,5 \times 10^{3}$ org. $\mathrm{mL}^{-1}$ (L9). No lago L8 foi encontrada a maior abundância de flagelados heterotróficos $\left(1,0 \times 10^{3}\right.$ org. $\left.\mathrm{mL}^{-1}\right)$ e no L9 a menor abundância $\left(7,1 \times 10^{1}\right.$ org. $\left.\mathrm{mL}^{-1}\right)$.

Não foram encontrados ciliados nas amostras dos lagos L1, L5, L7 e L9. Nos demais lagos, seus valores variaram entre $4,1 \times 10^{2}$ org. $\mathrm{mL}^{-1}$ (L8) e $1,5 \mathrm{X}$ $10^{2}$ org. $\mathrm{mL}^{-1}(\mathrm{~L} 6)$. No lago $\mathrm{L} 2$ foi encontrado o menor valor $\left(1,6 \times 10^{1}\right.$ org. $\left.\mathrm{mL}^{-1}\right)$ (Figura 3).

A

Flagelados autotrófic os

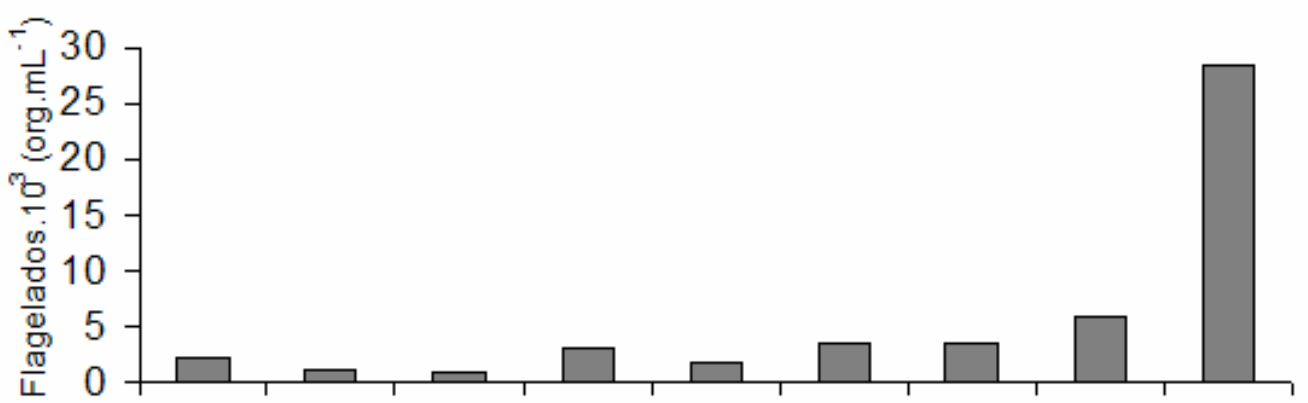

B

Flagelados heterotróficos
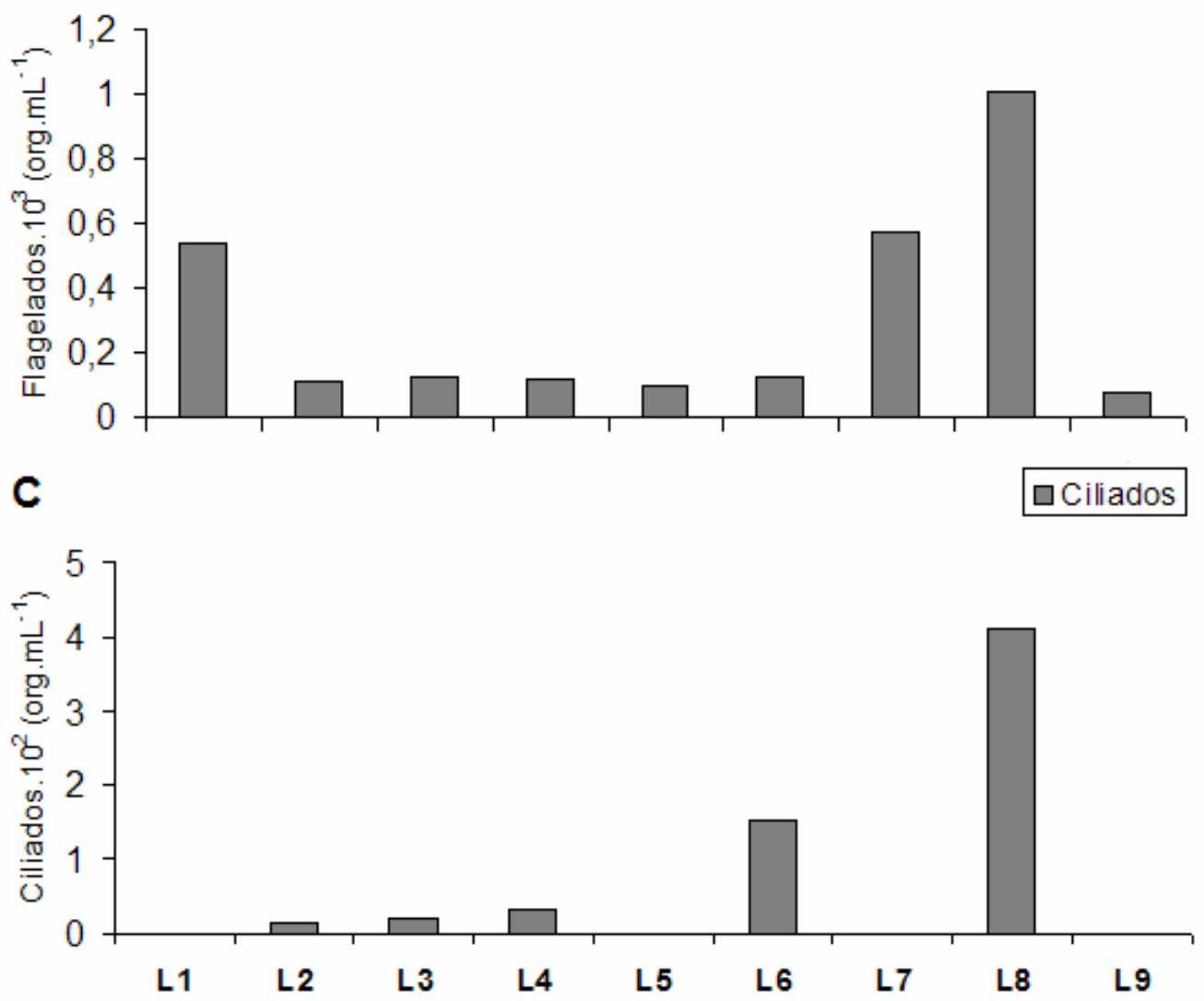

Figura 3: Densidade de flagelados autotróficos $\left(x 10^{3}\right.$ org. $\left.\mathrm{mL}^{-1}\right)(\mathrm{A})$, heterotróficos $\left(\mathrm{x} 10^{3}\right.$ org. $\left.\mathrm{mL}^{-1}\right)(B)$ e ciliados (x $10^{2}$ org. $\left.\mathrm{mL}^{-1}\right)(\mathrm{C})$ em nove lagos do Campus Carreiros em 10 de setembro de 2007. 


\section{Relações entre abundância bacteriana,} protozoários e fatores bióticos e abióticos

Uma forte correlação entre a abundância de bactérias livres e a concentração de fosfato dissolvido (Figura 4) (Tabela 2) foi encontrada em todos os lagos analisados. Porém, quando retirados os dados correspondentes aos lagos L1 e L7, que apresentaram as maiores concentrações de fosfato, esta relação não se confirma $\left(r^{2}=0,11 ; p<0,45\right)$.

Tabela 2. Valores do Coeficiente de Determinação $\left(r^{2}\right)$ e nível de significância das relações da abundância de bactérias, flagelados e ciliados com os fatores físico-químicos e bióticos.

\begin{tabular}{|c|c|c|c|c|c|c|c|c|c|c|c|c|c|c|c|c|c|c|}
\hline & \multicolumn{2}{|c|}{$\begin{array}{c}\text { Bactérias } \\
\text { Livres }\end{array}$} & \multicolumn{2}{|c|}{ Cocos } & \multicolumn{2}{|c|}{ Bacilos } & \multicolumn{2}{|c|}{ Víbrios } & \multicolumn{2}{|c|}{ Filamentosas } & \multicolumn{2}{|c|}{$\begin{array}{l}\text { Bactérias } \\
\text { Aderidas }\end{array}$} & \multicolumn{2}{|c|}{$\begin{array}{l}\text { Flagelados } \\
\text { Autotróficos }\end{array}$} & \multicolumn{2}{|c|}{$\begin{array}{c}\text { Flagelados } \\
\text { Heterotróficos }\end{array}$} & \multicolumn{2}{|c|}{ Ciliados } \\
\hline & $\mathrm{R} 2$ & $p$ & r2 & $p$ & r2 & $p$ & r2 & $\mathrm{p}$ & r2 & $\mathrm{p}$ & r2 & $\mathrm{p}$ & r2 & $p$ & r2 & $\mathrm{p}$ & r2 & $\mathrm{p}$ \\
\hline Seston $\left(\mathrm{mg} \cdot \mathrm{L}^{-1}\right)$ & 0,12 & 0,35 & 0,21 & 0,02 & 0 & 0,086 & 0,01 & 0,73 & 0,15 & 0,29 & 0,35 & 0,09 & 0,1 & 0,79 & 0,03 & 0,64 & 0,41 & 0,05 \\
\hline Oxigênio (mg. $\left.\mathrm{L}^{-1}\right)$ & 0,31 & 0,09 & 0,41 & 0,05 & 0,07 & 0,47 & 0,18 & 0,25 & 0,36 & 0,08 & 0,31 & 0,11 & 0,04 & 0,57 & 0,1 & 0,39 & 0,73 & 0,003 \\
\hline $\mathrm{pH}$ & 0,44 & 0,05 & 0,45 & 0,04 & 0,17 & 0,25 & 0,11 & 0,36 & 0,57 & 0,01 & 0,01 & 0,93 & 0,01 & 0,76 & 0,01 & 0,72 & 0,18 & 0,25 \\
\hline Condutividade ( $\mu$ mhos) & 0,15 & 0,29 & 0,13 & 0,33 & 0,13 & 0,33 & 0,004 & 0,86 & 0,04 & 0,52 & 0,26 & 0,16 & 0,01 & 0,76 & 0,19 & 0,23 & 0,13 & 0,34 \\
\hline Amônio $(\mu \mathrm{M})$ & 0,006 & 0,84 & 0,003 & 0,88 & 0,01 & 0,78 & 0,003 & 0,87 & 0,03 & 0,62 & 0,28 & 0,13 & 0,18 & 0,25 & 0,29 & 0,12 & 0,28 & 0,13 \\
\hline Nitrito $(\mu \mathrm{M})$ & 0,03 & 0,62 & 0,02 & 0,7 & 0,01 & 0,73 & 0,05 & 0,55 & 0,26 & 0,16 & 0,02 & 0,68 & 0,59 & 0,01 & 0,2 & 0,71 & 0,008 & 0,81 \\
\hline Nitrato $(\mu \mathrm{M})$ & 0,12 & 0,34 & 0,11 & 0,37 & 0,01 & 0,5 & 0,05 & 0,05 & 0,06 & 0,49 & 0,09 & 0,43 & 0,01 & 0,79 & 0,06 & 0,5 & 0,03 & 0,62 \\
\hline Fosfato $(\mu \mathrm{M})$ & 0,75 & 0,002 & 0,52 & 0,02 & 0,86 & 0 & 0 & 0,96 & 0,37 & 0,07 & 0,19 & 0,24 & 0 & 0,91 & 0,17 & 0,26 & 0,04 & 0,57 \\
\hline Clorofila a $\left(\mu \mathrm{g} \cdot \mathrm{L}^{-1}\right)$ & 0,005 & 0,84 & 0,03 & 0,62 & 0,01 & 0,84 & 0 & 0,96 & 0,13 & 0,33 & 0,16 & 0,28 & 0,01 & 0,85 & 0 & 0,95 & 0,09 & 0,41 \\
\hline
\end{tabular}

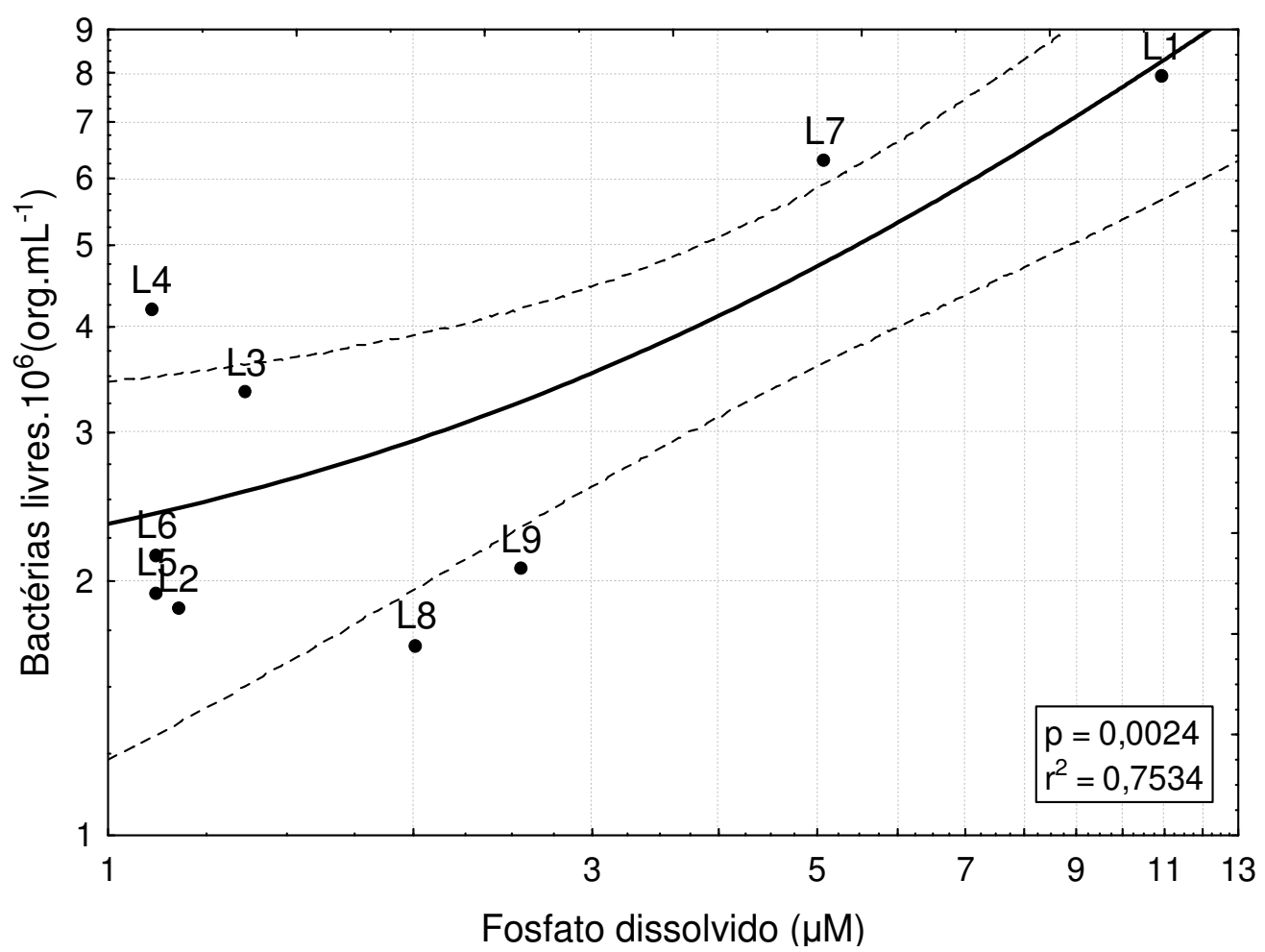

Figura 4: Relação entre bactérias livres e fosfato dissolvido em nove lagos do Campus Carreiros em 10 de setembro de 2007 (escala logarítmica).

Para as bactérias aderidas a partículas, ficou clara uma relação negativa entre estas e o oxigênio
Correlacionando os dados de abundância dos diferentes tipos morfológicos de bactérias livres com a concentração de fosfato dissolvido, observa-se uma forte relação deste elemento com os bacilos e cocos (Tabela 2), mas novamente o lago L1 teve um grande peso no estabelecimento destas correlações. As formas filamentosa e víbrio não apresentaram correlação significativa com o fosfato (Tabela 2). 


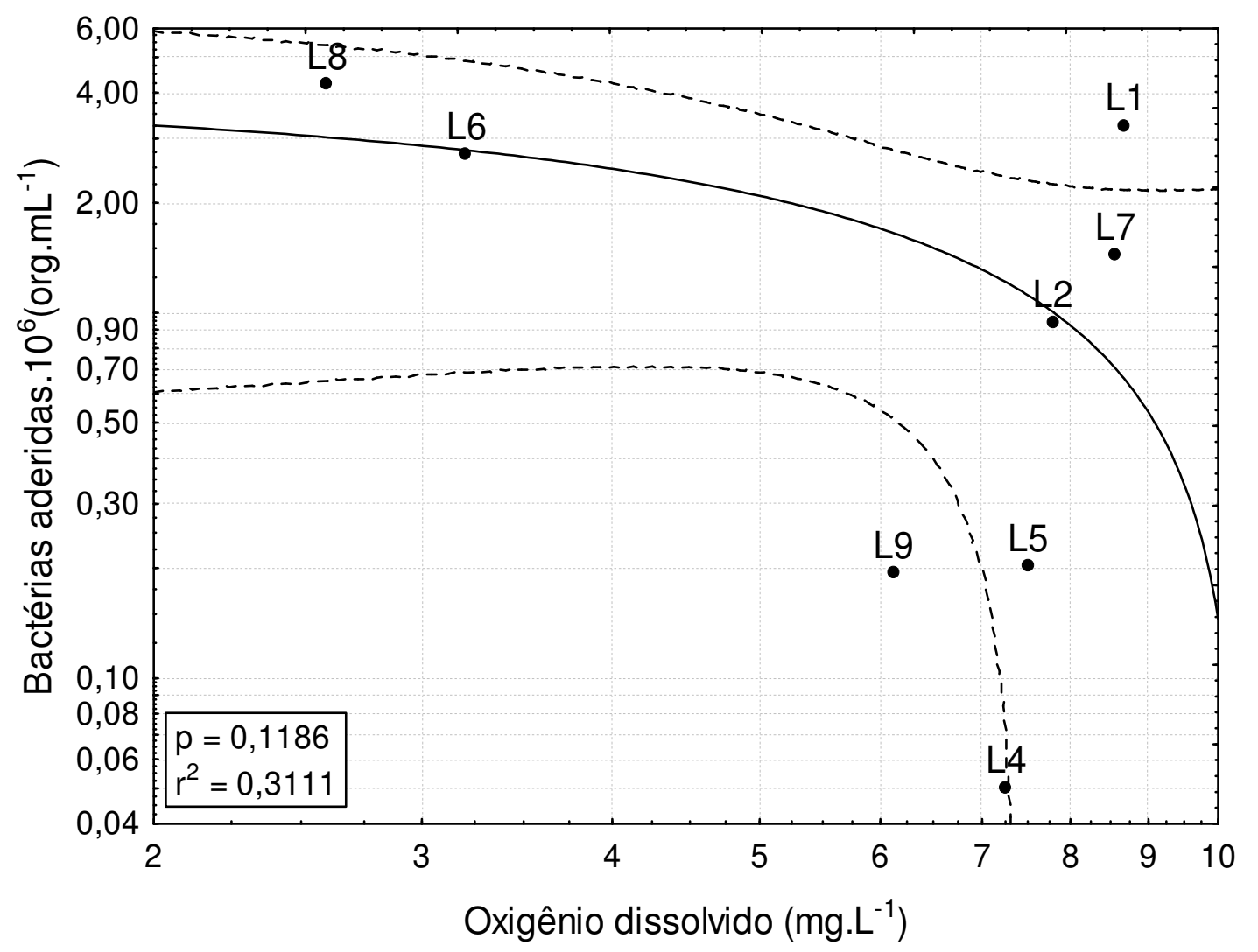

Figura 5: Relação entre bactérias aderidas e oxigênio dissolvido em nove lagos do Campus Carreiros em 10 de setembro de 2007 (escala logarítmica).

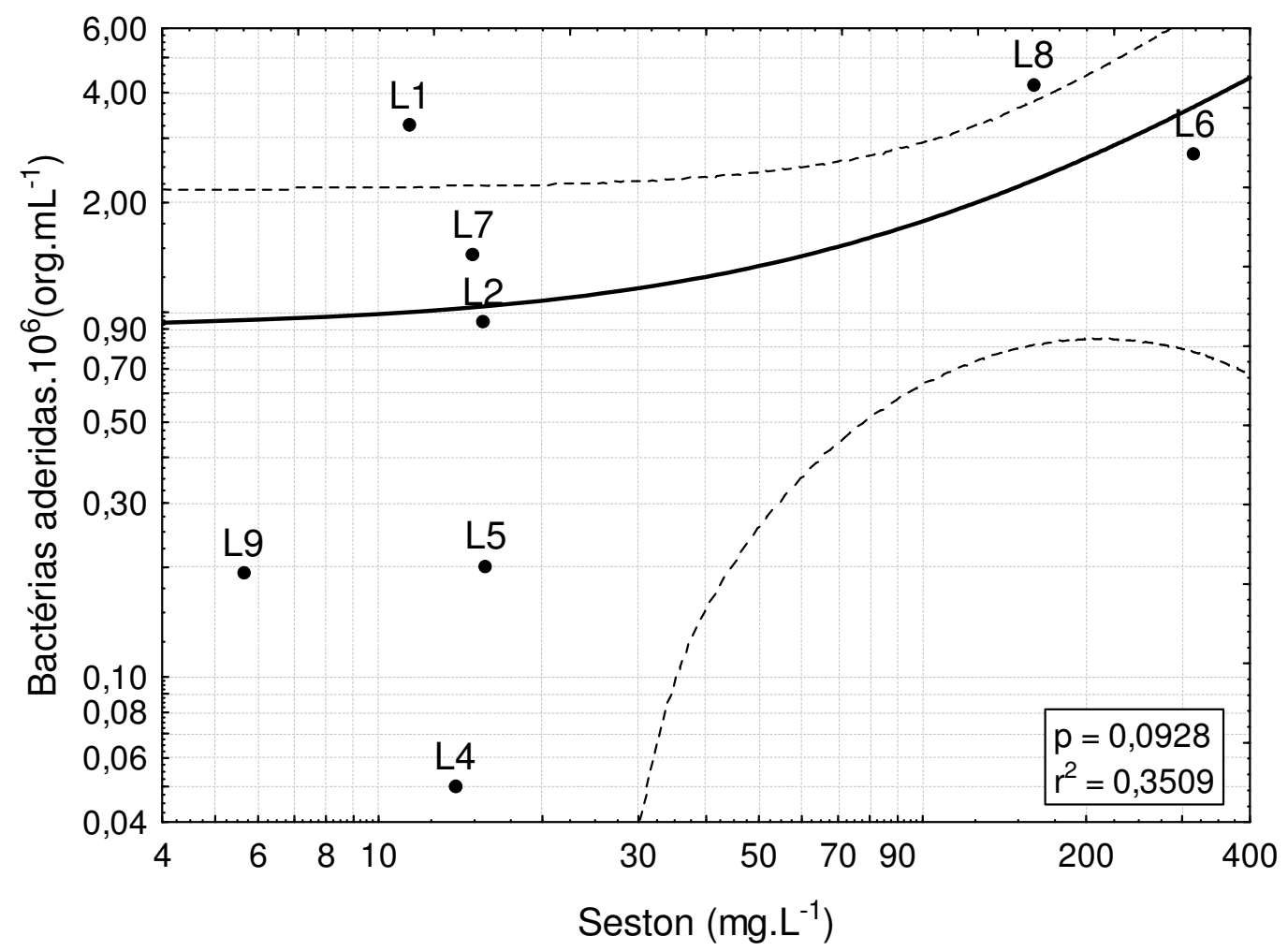

Figura 6: Relação entre bactérias aderidas e seston em nove lagos do Campus Carreiros em 10 de setembro de 2007 (escala logarítmica).

Entre as bactérias livres e um de seus possíveis predadores, os flagelados heterotróficos, 
não se verificou nenhuma relação (Tabela 2). Todavia, encontrou-se uma forte correlação da abundância de bactérias aderidas tanto com 0 número de flagelados heterotróficos (Figura 7) (Tabela 2) quanto com o número de ciliados (Figura 8) (Tabela 2).

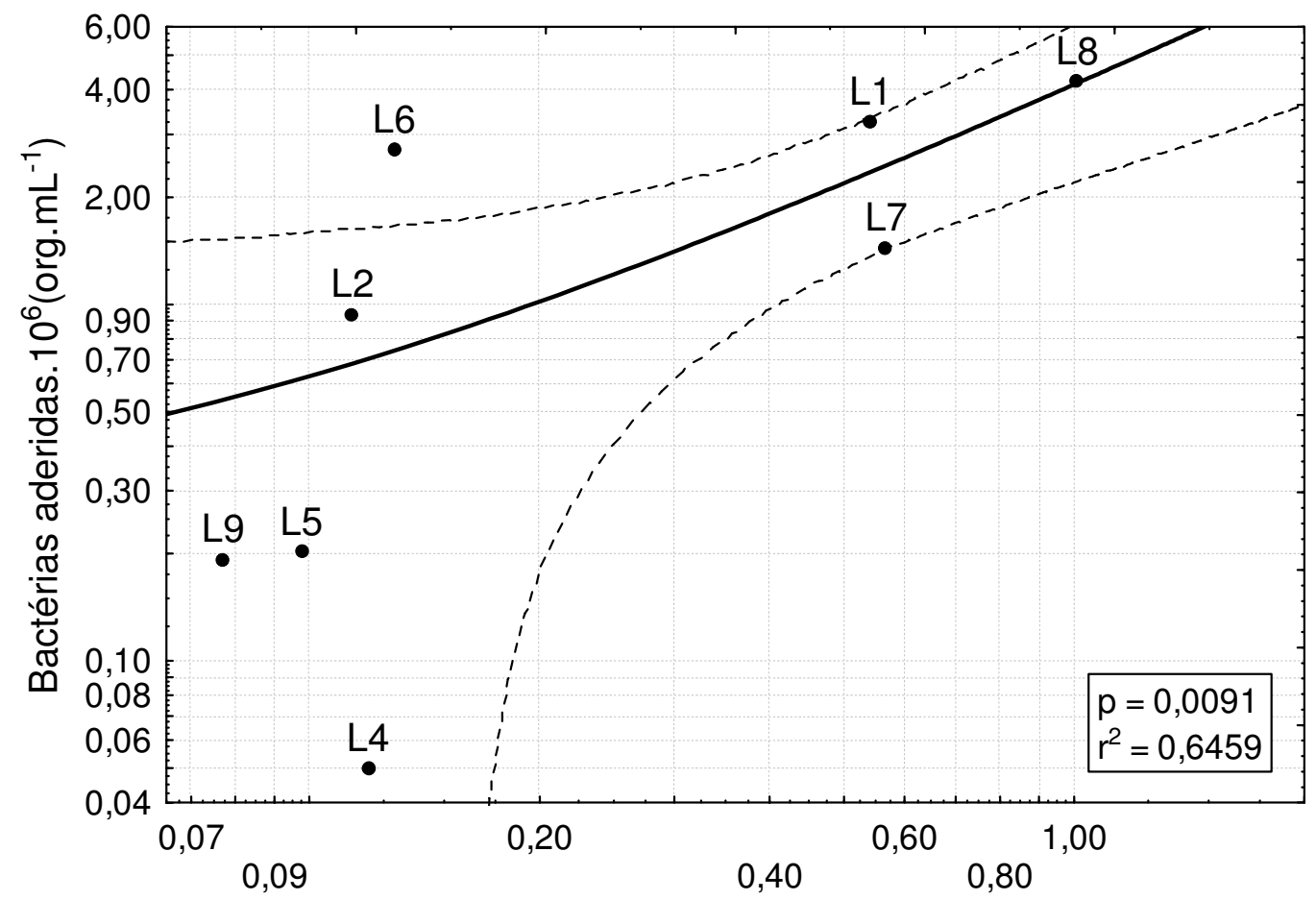

Flagelados heterotróficos. $10^{3}$ (org. $\mathrm{mL}^{-1}$ )

Figura 7: Relação entre bactérias aderidas e flagelados heterotróficos em nove lagos do Campus Carreiros em 10 de setembro de 2007 (escala logarítmica).

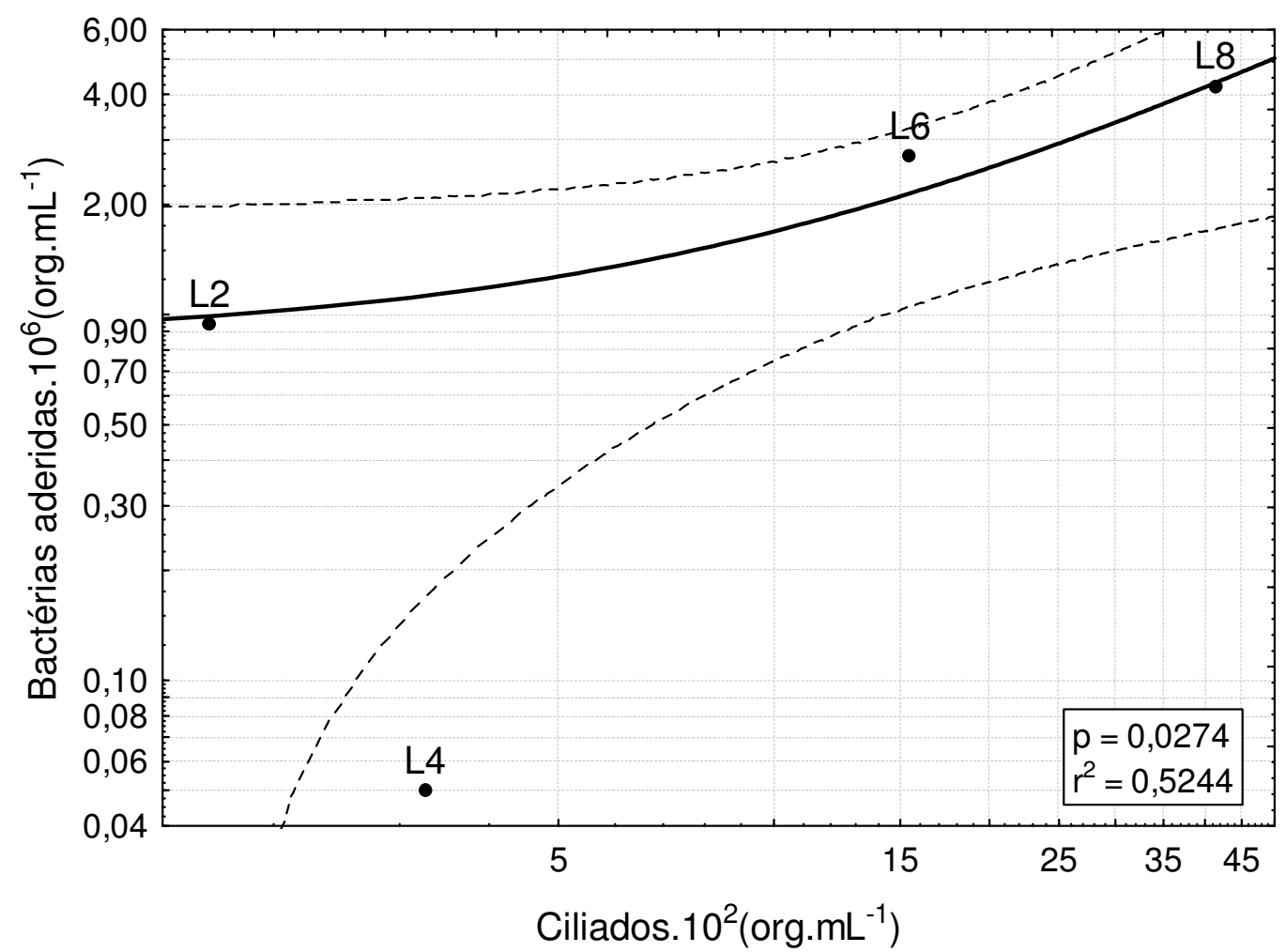

Figura 8: Relação entre bactérias aderidas e ciliados em nove lagos do Campus Carreiros em 10 de setembro de 2007 (escala logarítmica). 
Para os ciliados foi constatada uma forte relação negativa com o oxigênio dissolvido (Tabela 2 ) e uma relação positiva com o seston (Tabela 2). A única relação significativa encontrada para os flagelados autotróficos foi com o nitrito dissolvido (Tabela 2).

Outra relação importante foi dos flagelados heterotróficos com os ciliados (Tabela 2), a qual se mostrou mais significativa com a retirada dos dados dos lagos $L 1$ e $L 7\left(r^{2}=0,87 ; p<0,02\right)$.

\section{DISCUSSÃO}

Uma das principais características de lagos eutrofizados é a alta concentração de organismos fitoplanctônicos que crescem aceleradamente em função do aporte de nutrientes. Em ambientes lacustres, dentre os principais fatores que controlam a comunidade fitoplanctônica estão a disponibilidade de nutrientes, a iluminação subaquática e a variação sazonal da temperatura, podendo a herbivoria e o parasitismo também influenciar (Esteves 1998).

Em um estudo realizado por Santos (2003) nos mesmos nove lagos analisados nesta pesquisa, foi encontrada uma relação positiva da clorofila a com a área dos ambientes estudados, porém esta relação pode estar associada com a concentração do nitrogênio total encontrado, uma vez que os lagos maiores, como os lagos L1, L2 e L3, apresentaram os maiores valores de nitrogênio total. Entretanto, em nosso estudo, não foi verificada nenhuma correlação forte entre a clorofila a e os nutrientes analisados.

Nesta pesquisa, os valores de clorofila $a$ medidos $(7,8 \mu \mathrm{g} / \mathrm{L}$ - 169,18 $\mu \mathrm{g} / \mathrm{L})$ foram muito superiores àqueles obtidos por Santos (2003), que encontrou um mínimo de 2,9 $\mu \mathrm{g} / \mathrm{L}$ e um máximo de 18,7 $\mu \mathrm{g} / \mathrm{L}$. Esta discrepância pode ter sido resultado da eutrofização destes lagos, ou ser devido a uma variação sazonal da biomassa fitoplanctônica, uma vez que este estudo foi realizado ao final do inverno, enquanto que o de Santos (2003) foi realizado no final da primavera de 2001, provavelmente em um momento posterior ao máximo de clorofila a que pode ocorrer na primavera (Esteves 1998). Furlanetto (2006), ao estudar as variações sazonais do lago L2, observou que as concentrações de clorofila a variam bastante, sendo maiores em períodos de temperatura elevada. Dessa forma, estes dados demonstram a necessidade de um acompanhamento a longo prazo, para assim entendermos melhor o metabolismo destes ambientes.

Cabe ressaltar ainda que o método utilizado para a extração da clorofila a neste projeto não foi o mais adequado para ambientes de água doce com presença de grandes quantidades de cianobactérias. Melhor seria utilizar etanol a frio, ou aquecido, já que este pode ser mais eficiente na extração da clorofila a destes microorganismos (Paranhos 1996). Contudo, a comparação com o trabalho de Santos (2003) é satisfatória, já que este autor também utilizou acetona $90 \%$.

Verificou-se ainda que não existiu relação direta entre a clorofila a e a abundância bacteriana. Esta falta de relação também foi evidenciada por Abreu et al. (1992), Farjalla (2001) e Faria \& Esteves (2001) em diferentes ambientes aquáticos onde o fitoplâncton não é o principal fornecedor de carbono orgânico dissolvido (COD) para as bactérias. Desta maneira, pode-se supor que o principal aporte de COD dos lagos do Campus Carreiros provenha da decomposição de macrófitas aquáticas e de outros vegetais do entorno dos lagos.

A relação direta evidenciada entre as bactérias aderidas e o material em suspensão, pode ter sido influenciada pelos resultados obtidos para os lagos L6 e L8, os únicos que apresentaram a abundância de bactérias aderidas superior a de bactérias livres. Esta relação deve-se ao fato de que partículas orgânicas e inorgânicas proporcionam um substrato para o crescimento bacteriano. Ao mesmo tempo, é evidente uma relação negativa entre as bactérias aderidas e o oxigênio dissolvido, indicando a ação destes microorganismos na decomposição da matéria orgânica e na formação de zonas hipóxicas ou anóxicas nestes lagos. Tais relações não foram encontradas para as bactérias livres, o que sugere que são diferentes os fatores controladores da abundância de bactérias livres e aderidas (Abreu et al. 1992, Anésio et al. 2003).

Também foi encontrada uma forte relação entre bactérias aderidas e os flagelados heterotróficos e ciliados devendo-se, provavelmente, à predação exercida por estes dois grupos (Abreu et al. 1992). Tal relação pode ser explicada pelo fato das bactérias 
aderidas apresentarem maior biovolume (Simon 1987, Abreu et al. 1992, Seleghim 2001), o que facilita a sua predação por organismos maiores, sugerindo um controle "Top-Down". A abundância de bactérias aderidas e sua relação com flagelados e ciliados ressalta a importância destas para a cadeia alimentar detritívora nestes ambientes, onde a produção autotrófica não consumida por heterótrofos maiores é degradada e absorvida pelas bactérias e, em seguida, direcionada a níveis tróficos superiores através da predação destas por protozoários. Bactérias aderidas também podem ser importantes na melhoria da qualidade nutricional dos detritos e, assim, favorecer os animais filtradores e detritívoros com proteínas, aminoácidos essenciais e ácidos graxos (Simon 1987, Abreu et al. 1992, Brum \& Esteves 2001, Anésio et al. 2003).

Para as bactérias livres foi encontrada uma relação significativa apenas com o fosfato dissolvido, - que pode representar um controle "Bottom-Up" (Tzaras \& Pick 1994, Carlsson \& Caron 2001, Farjalla et al. 2001, Cesar 2002). Esta relação pode ser explicada por ser este um dos nutrientes essenciais ao crescimento bacteriano e muitas vezes limitado no ambiente (Esteves 1998). Contudo, quando retirados os dados referentes aos lagos $L 1$ e $L 7$, isto não se confirma, possivelmente devido ao fato de que nestes dois lagos os valores de fosfato são muito superiores aos encontrados nos demais ambientes. Entretanto, fica claro que os lagos com maiores concentrações de fosfato apresentavam também maior abundância de bactérias livres, o que pode significar que estes microorganismos atuam de maneira mais direta na ciclagem deste nutriente, como observado em outro estudo realizado sobre a decomposição de macrófitas no estuário da Lagoa dos Patos (Anésio et al., 2003).

Quando analisadas as relações do fosfato dissolvido com as diferentes formas de bactérias de vida livre nos nove lagos, foi evidenciado que tal relação teve maior influência na abundância de bacilos, seguido por cocos, enquanto que bactérias de outras formas como filamentosas e víbrios não apresentaram relação direta com a concentração de fosfato. Isto demonstra que diferentes fatores podem influenciar a abundância das distintas formas, ou talvez diferentes espécies de bactérias. Como exemplo pode-se citar o fato de que Farjalla (2001) achou uma predominância de longas bactérias filamentosas em lagoas costeiras com altas concentrações de sal. Além disso, diversos estudos sugerem que modificações na forma e no tamanho das bactérias é uma resposta à disponibilidade de nutrientes e/ou pressão de predação (Jüergens et al. 1994, Cesar \& Abreu 2001, Corno \& Jürgens 2005).

Para as bactérias livres não foi encontrada nenhuma relação com os flagelados e ciliados. Isto provavelmente deve-se ao fato de que estas apresentavam uma alta proporção de bactérias de pequeno tamanho, o que pode ser o resultado de uma estratégia de fuga da predação (Abreu et al. 1992).

Dentre os flagelados, os mais abundantes foram os autotróficos, tendo destaque os do lago L9 no qual a densidade de tais organismos foi quase seis vezes maior do que no lago com a segunda maior abundância. A relação encontrada entre estes microorganismos e o nitrito foi influenciada pelo valor mais alto deste nutriente ter sido encontrado no lago L9.

Outra importante relação encontrada foi entre os flagelados heterotróficos e os ciliados. Tal relação pode ser o resultado de uma predação dos flagelados pelos ciliados como observado em outros ambientes (Riemann \& Christoffersen 1993, Abreu \& Odebrecht 1998, Seleghim 2001, Pereira et al. 2005, Zingel et al. 2006).

Para os ciliados encontrou-se uma relação negativa com o oxigênio dissolvido e outra positiva com o seston, da mesma forma como observado para as bactérias aderidas a partículas. Tais evidências indicam que estes organismos podem estar atuando como potenciais predadores das bactérias aderidas. Zingel et al. (2006) em estudo realizado em um lago raso temperado destacou que os ciliados são importantes componentes da alça microbiana quando há uma alta concentração de seston no ambiente.

Em resumo, pode-se dizer que existe uma diferença significativa na abundância da comunidade microbiana entre os nove lagos estudados, além de uma diferença dos papéis desempenhados pelas bactérias livres e bactérias aderidas nestes ambientes. Destacamos a importância das bactérias livres como mineralizadoras e responsáveis pela circulação dos nutrientes, entretanto há limitação de seu crescimento pela disponibilidade de fosfato, 
caracterizando um controle "Bottom-Up" destes microorganismos. Por outro lado, as bactérias aderidas atuam principalmente na decomposição de matéria orgânica particulada, transferindo grande parte da energia contida nos detritos para níveis tróficos superiores através de interações tróficas com flagelados e, principalmente, ciliados. Estes microorganismos devem ter importante papel na cadeia detritívora especialmente dos lagos que apresentam maiores quantidades de material em suspensão e sua abundância deve estar sendo controlada pela predação, o que caracteriza um tipo de controle "Top-Down".

\section{AGRADECIMENTOS}

Os autores agradecem o apoio do Conselho Nacional de Pesquisa e Desenvolvimento ( $\mathrm{CNPq}$ ), aos técnicos do Laboratório de Ecologia do Fitoplâncton e Microorganismos Marinhos da FURG e as sugestões e críticas feitas por dois revisores anônimos. P.C. Abreu é Bolsista de Produtividade do CNPq.

\section{LITERATURA CITADA}

ABREU, PC, BA BIDDANDA \& C ODEBRECHT. 1992. Bacteria dynamics of the Patos lagoon estuary, southwestern Brazil: relationship with phytoplankton and suspended material. Estuar. Coastal and Shelf Sci., 35: 621-635.

ABREU, PC \& C ODEBRECHT. 1998. Bactérias e Protozooplâncton. In: SEELIGER, U, C ODEBRECHT \& JP CASTELLO (ed). Os Ecossistemas Costeiros e Marinho do Extremo Sul do Brasil. Editora Ecoscientia, Brasil. 326p.

ANÉSIO, AM, PC ABREU \& BA BIDDANDA. 2003. The role of free and attachedmicroorganisms in the decomposition of estuarine macrophyte detritus. Estuar. Coastal and Shelf Sci., 56: 197-201.

AZAM, F, T FENCHEL, JG FIELD, JS GRAY, LA MEYER-REIL \& F THINGSTAD.1983. The ecological role of water-column microbes in the sea. Mar. Ecol. Prog. Ser, 10: 257-263.

BRÖNMARK, C \& L-A HANSSON. 1999. The Biology of Lakes and Ponds. New York. Oxford University Press. 216p.

BRUM, PR \& FA ESTEVES. 2001. Changes in abundance and biomass of the attachedbacterial community throughout the decomposition of three species of aquatic macrophytes. Oecologia Brasiliensis, 9: 77-95.

CARLSSON P \& DA CARON. 2001, Seasonal variation of phosphorus limitation ofbacterial growth in a small lake. Limnol. Oceanogr., 46: 108-120.

CESAR, DE \& PC ABREU. 2001. Ecology of aquatic microorganisms in sourthern Brazil: State of Art. Oecologia Brasiliensis, 9: 153-171.

CESAR, DE. 2002. Estrutura e dinâmica do bacterioplâncton e suas relações com nutrientes inorgânicos e predação no estuário da Lagoa dos Patos/RS. Tese de Doutorado - Programa de Pós Graduação em Oceanografia Biológica, Fundação Universidade Federal de Rio Grande. Rio Grande.

CORDAZZO, CV. \& U SEELINGER. 1995. Guia ilustrado da vegetação costeira no extremo sul do Brasil. Rio Grande, Editora da FURG, 275p.

CORNO, G \& K JÜRGENS. 2005. Direct and Indirect Effects of Protist Predation on Population Size Structure of a Bacterial Strain with High Phenotypic Plasticity. Appl. and Environ. Microbiol., 72: $78-86$.
ESTEVES, FA. 1998. Fundamentos de Limnologia. Rio de Janeiro. Interciência. 602p.

FARJALLA, VF, BM FARIA, FA ESTEVES \& RL BOZELLI. 2001. Bacterial density and biomass, and relations with abiotic factors, in 14 coastal lagoons of Rio de Janeiro State. Oecologia Brasiliensis, 9: 65-76

FARJALLA, VF, A ENRICH-PRAST, FA ESTEVES \& ACP CIMBLERIS. 2006. Bacterial growth and DOC consumption in a tropical coastal lagoon. Braz. J. Biol., 66(2A): 383-392

FARIA, BM \& FA ESTEVES. 2001. Dissolved organic carbon in two brazilian coastal lagoons: Sources and utilization for heterotrophic bacteria. Oecologia Brasiliensis. 9: 57-64.

FELIP, M, ML PACE \& JJ COLE. 1996. Regulation of planktonic bacterial growth rates: The effects of temperature and resources. Microb. Ecol., 31: 15-28.

FURLANETTO, LM. 2006. Variações nictemerais e sazonais das principais variáveis limnológicas de um pequeno lago oligotrófico raso do extremo sul do Brasil. Rio Grande, FURG, 27p. (Monografia de graduação em Ciências Biológicas).

GAO, G. B QIN, R SOMMARUGA \& R PSENNER. 2007. The bacterioplankton of Lake Taihu, China: abundance, biomass, and production. Hydrobiol., 581:177-188.

HOBBIE, JE, RJ DALEY \& S JASPERS. 1977. Use of Nuclepore filters for counting bacteria by fluorescence microscopy. Appl. Environ. Microbiol., 33: 225- 228.

JÜERGENS, K, H ARNDT \& KO ROTHHAUPT. 1994. ZooplanktonMediated Changes of Bacterial Community Structure. Microb. Ecol., 27: $27-42$.

KUUPPO-LEINIKKI, P. 1990. Protozoan grazing on planktonic bacteria and its impact on bacterial population. Mar. Ecol. Progr. Ser., 63: 227-238.

MESQUITA, HSL. 1987. Ecologia de bactérias na costa sudeste-sul brasileira. In: Ecossistemas da Costa Sul e Sudeste Brasileira: Síntese dos Conhecimentos. Cananéia. 339 - 427.

PARANHOS, R. 1996. Alguns métodos para análise da água: Rio de Janeiro:UFRJ, Sub-Reitoria de Ensino da Graduação e Corpo Discente/SR-1, 200p.il. (cadernos didáticos UFRJ;19).

PASSOW, U, L DE LA ROCHA, C ARNOSTI, H-P GROSSART, AE MURRAY \& A NGEL. 2007. Microbial dynamics in autotrophic and heterotrophic seawater mesocosmos. I. Effect of phytoplankton on the microbial loop. Aquat. Microb., Ecol. 49: 109-121.

PEREIRA, DN, LFM VELHO, TA PAGIORO \& FA LANSAC-TÔHA. 2005. Abundância de nanoflagelados heterotróficos no plâncton de reservatórios com distintos graus de trofia. Acta Scientiarum. Biological Sciences, 27: 43-50.

RIEMANN, B \& K CHRISTOFFERSEN. 1993. Microbial trophodynamics in temperate lakes. Mar. Microb. Food Webs, 7(1): 69-100.

SANDERS, RW, DA CARON \& U-G BERNINGER. 1992 Relatinships between bacteria and heterotrophic nanoplankton in marine and fresh waters: an inter-ecosystem comparison. Mar. Ecol. Progr. Ser., 86: 1 - 14.

SANTOS, GS. 2003. Comparação do Fitoplâncton e Fatores Abióticos em Ecossistemas Lacustres do Campus Carreiros, Rio Grande, RS (novembro de 2001). Rio Grande, FURG, 44p (Monografia de graduação em Oceanologia).

SEELINGER, U \& C ODEBRECHT. 1998. Introdução e Aspectos Gerais. In: SEELIGER, U, C ODEBRECHT \& JP CASTELLO (ed). Os Ecossistemas Costeiros e Marinho do Extremo Sul do Brasil. Editora Ecoscientia, Brasil. 326p.

SELEGHIM, MHR. 2001. Rede trófica microbiana em um sistema eutrófico raso (Reservatório do Monjolinho - São Carlos - São Paulo) - Estrutura e função. Tese de doutorado - Programa de Pós Graduação em Ecologia e Recursos Naturais, Universidade Federal de São Carlos. São Carlos.

SIMON, M. 1987. Biomass and production of small and large freeliving and attached bacteria in Lake Constance. Limnol. Oceanogr., 32(3): 591-607.

SNEDECOR, GW \& WG COCHRAN. 1980. Statistical Methods. Ames. lowa State. 507p. 
STRICKLAND, JDH \& TR PARSONS. 1972. A practical handbook of seawater analysis. Ottawa, Fisheries Research Board of Canada. Bulletin 167, $310 \mathrm{p}$

TRINDADE, C. 2005. Variações nictemerais e sazonais das principais variáveis limnológicas do lago dos Biguás, Campus Carreiros, FURG - RS. Rio Grande, FURG, 20p (Monografia de graduação em Ciências Biológicas).

TZARAS, A \& FR PICK. 1994. The relations between bacterial and heterotrophic flagellate abundance in oligotrophic to mesotrophic temperate lakes. Mar.Microb. Food Webs., 8: 347-355.

UNESCO. 1983. Chemical methods for use in marine environmental monitoring.Intergovernmental Oceanographic Comission. Manual and Guides, 12, 337 p.

UTERMÖHL, H. 1958. Zur Vervollkommnung der quantitativen phytoplankton -Methodik. Mitteilungen der internationalen Vereinigung für theoretische und angewandte Limnologie, 9:1 - 38 .

ZINGEL, P, H AGASILD, T NÕGES \& V KISAND. 2006. Ciliates are the dominant grazers on pico - and nanoplankton in a shallow, naturally highly eutrophic lake. Microb. Ecol., 53: 134-142.

WELSCHMEYER, N.A. 1994. Fluorometric analysis of chlorophyll a in the presence of chlorophyll $b$ and phaeopigments. Limnol. Oceanogr., 39 (8): 1985-1992.

Recebido: 15/04/2008

Aceito: 04/06/2009 
NEUSIANE CHAVES DE SOUZA \& PAULO CESAR ABREU 